\title{
Interannual variability of dissolved and rice grain concentrations of arsenic and cadmium in paddy fields subjected to different water managements
}

\author{
T. Honma ${ }^{1}$, K. Nakamura ${ }^{2}$, T. Makino ${ }^{2} \&$ H. Katou ${ }^{2}$ \\ ${ }^{1}$ Niigata Agricultural Research Institute, Nagaoka, Japan \\ ${ }^{2}$ Institute for Agro-Environmental Sciences, NARO, Tsukuba, Japan
}

\begin{abstract}
Interannual variability of dissolved arsenic (As) and cadmium (Cd) concentrations as well as those in rice grain was investigated in paddy fields subjected to different water managements. While substantial variability was observed in the $\mathrm{As}$ and $\mathrm{Cd}$ concentrations, unique relationships existed between dissolved and rice grain concentrations across different years and water managements. The results suggest that interannual variability of dissolved $\mathrm{As}$ and $\mathrm{Cd}$ concentrations was responsible for the variability in the concentrations in rice grain and should be taken into account in risk assessment.
\end{abstract}

\section{INTRODUCTION}

Arsenic and $\mathrm{Cd}$ accumulation in rice grain is of serious concern to human health. Because of anaerobic conditions prevailing in rice growing fields, rice can accumulate a higher concentration of inorganic arsenic (iAs), a human carcinogen, than other cereal crops. The uptake of $\mathrm{As}$ and $\mathrm{Cd}$ by rice is sensitive to redox conditions in soil and affected by water management during growth period. Reducing conditions produced by flooding lead to increase in As solubility through reductive dissolution of As-sorbing iron (III) (hydr)oxides and decrease in Cd solubility through formation of hardly soluble cadmium sulfide, while oxidizing conditions produced by drainage promote immobilization of As and solubilization of Cd. Honma et al. (2016) conducted field experiments to compare the effects of intermittent irrigation with different irrigation intervals. They found that concentrations of As and $\mathrm{Cd}$ in rice grain were linearly related to dissolved concentrations during postheading 3 weeks and suggested an optimal Eh of $-73 \mathrm{mV}$ for simultaneously suppressing rice grain $\mathrm{As}$ and $\mathrm{Cd}$ concentrations. The objectives of the present study were to investigate (i) to what extents dissolved and rice grain $\mathrm{As}$ and $\mathrm{Cd}$ concentrations are interannually variable under the same water managements, and (ii) whether the relationships between dissolved $\mathrm{As}$ and $\mathrm{Cd}$ and rice grain iAs and $\mathrm{Cd}$, as well as the optimal Eh, are influenced by the interannual variability.

\section{METHODS/EXPERIMENTAL}

\subsection{Field experiments}

Field experiments were conducted in 2013 through 2015 in a paddy field on an alluvial plain in central Japan. The soil, classified as a Typic
Hydraquent (Soil Survey Staff, 2014), had a total carbon content of $16.2 \mathrm{~g} \mathrm{~kg}^{-1}, 1 \mathrm{M} \mathrm{HCl}$-extractable As of $2.49 \mathrm{mg} \mathrm{kg}^{-1}$, and $0.1 \mathrm{M} \mathrm{HCl}$-extractable $\mathrm{Cd}$ of $0.84 \mathrm{mg} \mathrm{kg}^{-1}$. The textural composition was $52 \%$ sand $(0.2-2 \mathrm{~mm}), 30 \%$ silt $(0.02-0.2 \mathrm{~mm})$, and $18 \%$ clay $(<2 \mathrm{~mm})$, with soil $\mathrm{pH}$ of 5.8 measured at a soil:water ratio of $1: 2.5$.

Seedlings of rice (Oryza sativa L. cv. Koshihikari) were transplanted in mid-May. The rice plants were grown under flooded conditions for approximately 5 weeks, followed by 14 days of midseason drainage. Thereafter, different water managements were practiced during preheading 3 weeks and postheading 3 weeks. They included (i) flooded (FLD), (ii) intermittent irrigations F3D3, F3D5, and F3D7, where numerals before the letters ' $F$ ' and ' $D$ ' designate the length (in days) of flooding and drainage in irrigation cycle, respectively, and (iii) rainfed (RFD). The water management F3D7 was not conducted in 2013 whereas F3D5 and F3D7 were not conducted in 2015. The field was drained for harvest in early September.

\subsection{Plant and soil analysis}

Rice grains air-dried to $15 \%$ of moisture and remaining on the $1.85 \mathrm{~mm}$-sieve were used for analysis. Inorganic $\mathrm{As}(\mathrm{III})$ and $\mathrm{As}(\mathrm{V})$ concentrations in the grains were determined by inductively coupled mass spectroscopy (ICP-MS) according to the methods of Nishimura et al. (2010) and Baba et al. (2014) after digestion with dilute $\mathrm{HNO}_{3}$. Total $\mathrm{Cd}$ concentration was determined by flow injection (FI)-ICP-MS after digestion with $\mathrm{HNO}_{3}$ followed by $\mathrm{H}_{2} \mathrm{O}_{2}$.

Soil redox potential (Eh) was measured in duplicate with platinum electrodes installed at a depth of $15 \mathrm{~cm}$ in the field. Soil solution samples were collected using solution samplers installed at the same depth, at intervals of 1-2 weeks from mid-June to early September. 
Immediately after collection, the samples were acidified with $\mathrm{HNO}_{3}$ and analyzed for total As and Cd by FI-ICP-MS.

\section{RESULTS AND DISCUSSION}

\subsection{Dissolved As and Cd}

In Figure 1, dissolved As and Cd concentrations averaged over postheading 3 weeks are plotted against soil Eh averaged over the same period for each water management in the three years. General trends of sharp decrease of dissolved As with soil Eh, particularly at Eh above $-100 \mathrm{mV}$, and gradual increase of dissolved $\mathrm{Cd}$ with Eh were evident across different years and water managements. However, both dissolved As and $\mathrm{Cd}$ concentrations showed considerable interannual variability, particularly in the plots where the concentrations were high (i.e., dissolved As in FLD and F3D3; dissolved Cd in F3D3 and RFD). The optimal soil Eh for simultaneously suppressing dissolved As and $\mathrm{Cd}$ concentrations was identified using the "trade-off value" proposed by Honma et al. (2016) and found at approximately $-50 \mathrm{mV}$. This value was in reasonable agreement with the previously reported value of $-73 \mathrm{mV}$ in the same field by Honma et al. (2016). Among the water managements compared in this study, intermittent irrigation F3D5 was most effective in simultaneously suppressing dissolved $\mathrm{As}$ and $\mathrm{Cd}$.

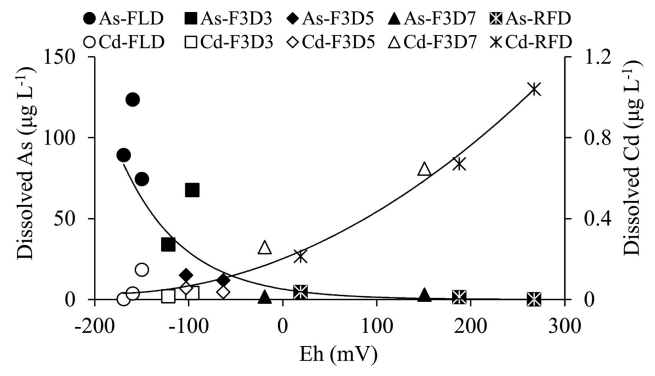

Figure 1. Relationships between dissolved As and Cd concentrations and soil Eh. Each symbol represents the average value for postheading 3 weeks in different water managements and years.

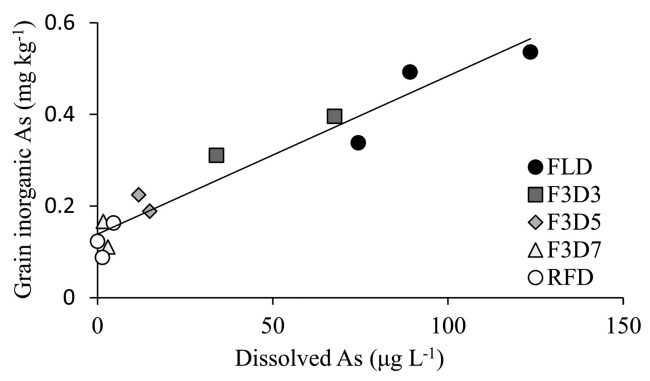

Figure 2. Relationship between inorganic As concentration in rice grain and dissolved As concentration across different water managements and years.

\subsection{Inorganic As and $C d$ in rice grain and their relations to dissolved $A s$ and $C d$}

Inorganic $\mathrm{As}$ and $\mathrm{Cd}$ concentrations in rice grain also showed considerable interannual variability. Nonetheless, across different water managements and years, there was a linear relationship between the average dissolved As concentration in the postheading 3 weeks and iAs concentration in rice grain (Fig. 2). A linear relationship was also observed between the average dissolved $\mathrm{Cd}$ concentration in the same period and rice grain $\mathrm{Cd}$ concentration. These results suggest that interannual variability of dissolved $\mathrm{As}$ and $\mathrm{Cd}$ concentrations was responsible for the variability in the $\mathrm{iAs}$ and $\mathrm{Cd}$ concentrations in rice grain. A larger interannual variability was found as the iAs and $\mathrm{Cd}$ concentrations increased, and this should be taken into account in risk assessment.

\section{CONCLUSIONS}

Both dissolved As and $\mathrm{Cd}$ concentrations in paddy soil and $\mathrm{iAs}$ and $\mathrm{Cd}$ concentrations in rice grain showed a substantial interannual variability under the same water managements. However, there were unique linear relationships for $\mathrm{As}$ and $\mathrm{Cd}$, across different water managements and years, between average dissolved concentrations during postheading 3 weeks, and concentrations in rice grain. This suggests that interannual variability of dissolved concentrations in response to variable weather and redox conditions was responsible for the variability in the concentrations in rice grain. A larger interannual variability is expected under water managements conductive to higher iAs and $\mathrm{Cd}$ concentrations, and this should be taken into account in risk assessment.

\section{ACKNOWLEDGEMENTS}

This work was supported by a grant from the Ministry of Agriculture, Forestry, and Fisheries of the Japanese Government (Research project for improving food safety and animal health As-240).

\section{REFERENCES}

Baba, K., Arao, T., Yamaguchi, N., Watanabe, E., Eun. H. \& Ishizaka, M. 2014. Chromatographic separation of arsenic species with pentafluorophenyl column and application to rice. J. Chromatogr. A 1354: 109-116.

Honma, T., Ohba, H., Kaneko-Kadokura, A., Makino, T., Nakamura, K. \& Katou, H. 2016. Optimal soil Eh, pH, and water management for simultaneously minimizing arsenic and cadmium concentrations in rice grains. Environ. Sci. Technol. 50(8): 4178-4185.

Nishimura, T., Hamano-Nagaoka, M., Sakakibara, N., Abe, T., Maekawa, Y. \& Yonetani, T. 2010. Determination method for total arsenic and partial-digestion method with nitric acid for inorganic arsenic speciation in several varieties of rice. J. Food Hyg. Soc. Jpn. 51(4): 178-181.

Soil Survey Staff. 2014. Keys to Soil Taxonomy, Twelfth Edition. U.S. Department of Agriculture, Natural Resources Conservation Service. 